\title{
Large right ventricular laceration during insertion of lariat device
}

\author{
Fahad Younas • Naba Rahman • Faisal H. Cheema • Atiq Rehman
}

Received: 2 November 2013 / Accepted: 27 February 2014 / Published online: 22 April 2014

(C) Springer Science+Business Media New York 2014

Keywords LARIAT procedure $\cdot$ Complications $\cdot$ Atrial fibrillation

Pericardial access-related complications have been reported in $4-5 \%$ of cases during percutaneous ligation of the left atrial appendage (LAA) with LARIAT device $(1,2)$. An 82 year-old lady with atrial fibrillation and contraindication to anticoagulation underwent LARIAT device insertion. Pericardial effusion was noted on transesophageal echocardiography soon after subxiphoid access. Pericardiocentesis was performed with auto-transfusion into the femoral vein for $90 \mathrm{~min}$ with no resolution of the effusion. Sternotomy was performed by the surgical team which revealed profuse active bleeding from a large RV laceration (Video). A 4-0 Prolene pledgeted suture was inserted to control the bleeding (Fig. 1). LAA was occluded with an Atriclip (Atricure Inc. Cincinnati, OH) $45 \mathrm{~mm}$ device (Fig 2). The patient had an uneventful postoperative course. This case emphasizes prompt surgical consultation in pericardial access-related complications during LARIAT device insertion.

Electronic supplementary material The online version of this article (doi:10.1007/s10840-014-9896-9) contains supplementary material, which is available to authorized users.

\section{F. Younas}

Department of Cardiology, St. Joseph Mercy Oakland, Pontiac, MI, USA

N. Rahman

Pine View School, Osprey, FL, USA

\section{F. H. Cheema}

University of Maryland Medical Center, Baltimore, MD, USA

\section{N. Rahman $\cdot$ A. Rehman}

Sarasota Memorial Hospital, Sarasota, FL, USA

\section{A. Rehman}

Columbia University College of Physicians and Surgeons, New York, NY, USA

\section{A. Rehman ( $\bowtie)$}

1540S Tamiami Trail, Suite 303, Sarasota, FL 34239, USA

e-mail: atiqmd@aol.com

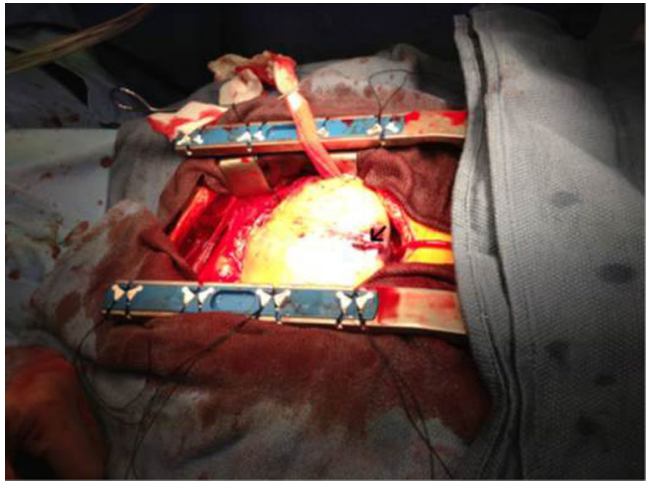

Fig. 1 Insertion of a 4-0 Prolene pledgeted suture to control bleeding

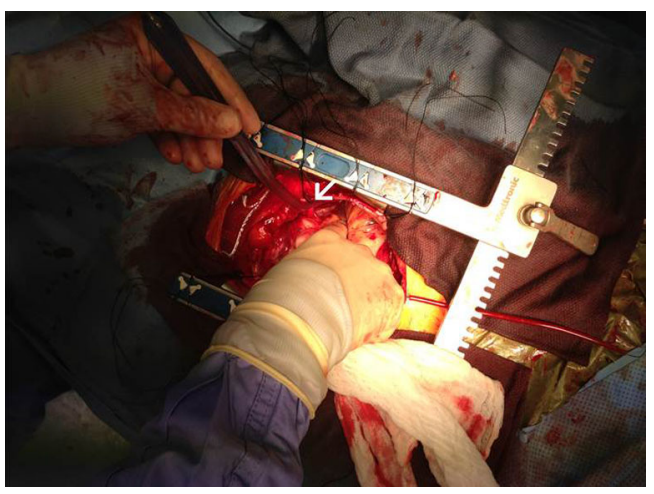

Fig. 2 Occlusion of the LAA with an Atriclip $45 \mathrm{~mm}$ device

\section{Support None}

Conflict of interest None of the authors have any financial or other potential conflicts of interest relative to the data in this manuscript.

\section{References}

1. Bartus, K., Han, F. T., Bednarek, J., et al. (2013). Percutaneous LAA suture ligation using LARIAT device in patients with atrial fibrillation: initial clinical experience. Journal of the American College of Cardiology, 62(2), 108-118.

2. Massumi, A., Chelu, M. G., Nazeri, A., et al. (2013). Initial experience with a novel percutaneous left atrial appendage exclusion device in a patient with atrial fibrillation, increased stroke risk and complications to anticoagulation. Am J Card, 111(6), 869-873. 